\title{
COMPUTATIONAL FLUID DYNAMICS AS A TOOL TO PREDICT THE AIR POLLUTION DISPERSION IN A NEIGHBORHOOD - A RESEARCH PROJECT TO IMPROVE THE QUALITY OF LIFE IN CITIES
}

\author{
G. TRISCONE ${ }^{1}$, N. ABDENNADHER ${ }^{1}$, C. BALISTRERI ${ }^{1}$, O. DONZÉ ${ }^{1}$, D. GRECO ${ }^{1}$, P. HAAS $^{1}$, \\ H. HAAS-PEKÖZ ${ }^{1}$, T. MOHAMED-NOUR ${ }^{1}$, P. MUNIER ${ }^{1}$, P. PONTELANDOLFO $^{1}$, R. PUTZU $^{1}$, \\ J. RICHARD ${ }^{1}$, H. STHIOUL ${ }^{1}$, N. DELLEY ${ }^{1}$, D. CHOFFAT ${ }^{1}$, E. NIEDERHÄUSER ${ }^{1}$, ROGER SCHAER ${ }^{1}$, \\ HENNING MÜLLER ${ }^{1}$, J. DECAIX ${ }^{1}$, S. RICHARD ${ }^{1}$, C. MÜNCH-ALLIGNÉ ${ }^{1}$, P. KUNZ $^{2}$ \& F. DESPOT ${ }^{3}$ \\ ${ }^{1}$ University of Applied Sciences Western Switzerland, Switzerland. \\ ${ }^{2}$ SABRA., Switzerland. \\ ${ }^{3}$ SEDE Ltd., Switzerland.
}

\begin{abstract}
In large cities, pollution composed of many different chemical components and small particles is an important public health problem that affects especially children and people presenting breathing difficulties.

One challenge for public authorities is to respect the norms given by the central state, but how? Today, concrete methods for reducing pollution are perceived by the majority of citizens as constraints. However, the authorities have the possibility of modifying the wind's action by imposing architectural constraints, such as building emplacement and roof structure. This is the main objective of the Geneva 'Clean City' project financed by the University of Applied Sciences Western Switzerland.

'Clean City' focuses its research on one of Geneva's polluted neighborhood called Pâquis, which is situated directly on the Geneva lake front. The project attempts to understand the dispersion of pollution from an experimental and a numerical point of view. After validation of the technique for a simple case, we compare environmental measurements on a 1/500 3D scale model of the Pâquis installed in an instrumented wind tunnel with Computational Fluid Dynamics (CFD) simulation obtained with the help of cloud computing.

Keywords: air pollution, CFD, polluants dispersion.
\end{abstract}

\section{INTRODUCTION}

As in many large cities around the world, the atmosphere of some neighborhoods is often badly polluted, especially during wintertime when the central heating systems are working. This is an important health concern for the state services in charge of air protection. But, as is well known, it is difficult, for many reasons, to take action that would bring the pollution levels to acceptable safe values. Because of that difficulty, millions of people are exposed every day to 'high' or 'very high' levels of air pollution. 
Since 2005, the World Health Organization (WHO) has provided guidelines concerning air quality and drinking water quality. Concerning air quality [1], the guidelines focus on different pollution gases such as ozone, nitrogen dioxide, sulphur dioxide, and particulate matter.

\subsection{Others studies in the same field}

There are an increasing number of research projects related to urban climate such as Clim [2], a project of the city of Paris. However, to our knowledge, they do not achieve the goal of providing a complete multidisciplinary tool for the decision-making process to aid the project planner on questions of air currents at the street level for the entire town.

Previously published studies have tried to solve the problem of calculating the temperature related to local albedo or have focused on experimental tests of air movements. Other projects (eg. ACCLIMAT [3]) try to predict local weather changes in terms of temperature, rainfall, etc. due to urban development [4]; but this is always in the context of global trends (problems of high granularity). Dispersion of pollutants using Computational Fluid Dynamics (CFD) is currently being studied by many research groups. See papers by Blocken et al. [5] or by Huijbregts et al. [6].

Other studies involve physical and/or coupling of different physical models to describe different situations while avoiding the problems associated with extensive computation time. See also Ref.[7].

\subsection{Clean city project}

In the Geneva Pâquis neighborhood, the air quality is generally poor for nitrogen dioxide and the PM10 particle pollutions, as shown in Fig. 1, even though this area is on the lakefront and exposed to wind! The left side of the Fig. 1 shows the $\mathrm{NO}_{2}$ concentration in air (average from 2004 to 2011) in Geneva [8]. The Pâquis neighborhood is situated under the red-brown area in Fig. 1. The right side of Fig. 1 shows the number of days per year when the PM10 concentration exceeded the legal limit $(50 \mu \mathrm{g} / \mathrm{m} 3)$ in town 'Urbain' area, in suburban 'Suburbain' area and in the country side 'Rural' [8]. At the present time, we do not understand why the air quality is so poor, and because of that, it is difficult to propose actions or constraints without knowing if the results will be significant.
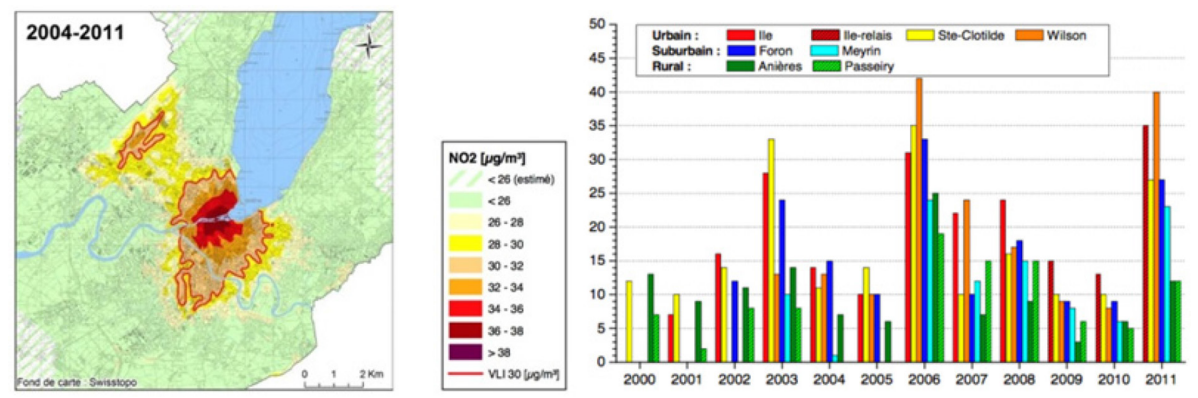

Figure 1: Average 2004 to $2011 \mathrm{NO}_{2}$ concentration in air in Geneva (left map) and number of days per year when the PM10 concentration exceeded the legal limit (right histogram). 
With the help of new powerful computers, the availability of cloud computing and many new breakthrough technologies, we believe that CFD may help to give a solution for town planners in charge of making the cities of tomorrow. This is the aim of this extensive research project, associating four Swiss engineering schools and two partners, one institutional and one commercial.

In this scientific report, we will show the first results of a CFD simulation for an entire neighborhood with a cell mesh not larger than 0.5 meter. The main idea of the project is to validate the simulation with measurements on a real experimental representation of the Pâquis area at a scale of 1/500 in a wind tunnel under well-defined conditions.

In case of success, these tools should help town planners to improve air currents in any town. They will also allow services in charge of air protection to justify their proposals.

\section{TOOLS WE SET UP TO RESOLVE THE PROBLEM}

To solve the problem we set up multidisciplinary teams in the fields of:

- Computer-aided design (CAD): model of the town obtained using Unmanned Aerial Vehicle (UAV) imagery that allows engineers to obtain 2D maps and 3D models with an accuracy of $5 \mathrm{~cm}$;

- CAD model with the help of the 'Territory Information System' called SIT Geneva [9];

- 3D printing to produce a $1 / 500$ scale model;

- Micro engineering team for the instrumentation needed on the model;

- Mechanical team for the wind tunnel experiments;

- Computer hardware team for providing the necessary computer power;

- Software development, especially for the flow model, turbulence, reactions, etc., using CFD simulation software, OpenFOAM [10];

- Consolidation of the results using commercial software, ANSYS Fluent [11];

- Surface and air pollution measurements with the help of an instrumented UAV.

Technical contributions from four University of Applied Sciences engineering schools of Western Switzerland, SEDE, Ltd., and the Geneva air protection service are acknowledged.

\section{EXPERIMENTAL}

\subsection{D CAD Pâquis Geneva neighborhood and the model made by rapid prototyping}

\subsubsection{From the SITG database}

As in many towns in Switzerland, Geneva has its own Information Territory System called SITG [9]. Using this data base, we can model the Pâquis neighborhood in 3D with a resolution on the order of one decimeter but with considerable manual work, especially when modeling two adjoining buildings to obtain usable CAD files. Finally, after much painstaking work, we were able to obtain acceptable CAD files which were used for the $3 \mathrm{D}$ prototyping and the CFD simulations.

\subsubsection{From the UAV's acquisition flights}

In order to work without having an Information Territory System and to be able to use the developed method in any location, we also obtained the CAD model using another method. To do that, we used a UAV R-Pod which acquired 250 orthophotos in 90 minutes at $140 \mathrm{~m}$ 
altitude and then generating the CAD 3D model with the help of three different software packages: Pix4D, Socet Set and Orima, (see Ref. [12] for more details). The Ground Sampling Distance (GSD: size of area represented by each pixel in a digital photo) was 5 $\mathrm{cm}$. Figure 2 shows the flight planning and the raw 3D objects.

Even if the model needs manual retouching, especially for adjoining buildings, the UAV method used to obtain the 3D CAD model of an entire neighborhood was successful. More details can be found in Ref. [13].

\subsubsection{D 1/500 Pâquis model}

The model was obtained using 3D rapid prototyping using a $\mathrm{Z}$ Printer 450 from 3D systems. The model shown in Fig. 3 is constituted of about 80 different $3 \mathrm{D}$ parts $25 \mathrm{~cm} \times 25$ $\mathrm{cm}$ each, joined together to obtain a neighborhood model about $2.7 \mathrm{~m}$ long and $1.9 \mathrm{~m}$ wide. The pollution caused by the central heating systems and road traffic are simulated in the model by one roof chimney per building connected to an SF6 pressurized gas bottle and by holes in the streets with the diffusion of the same gas.
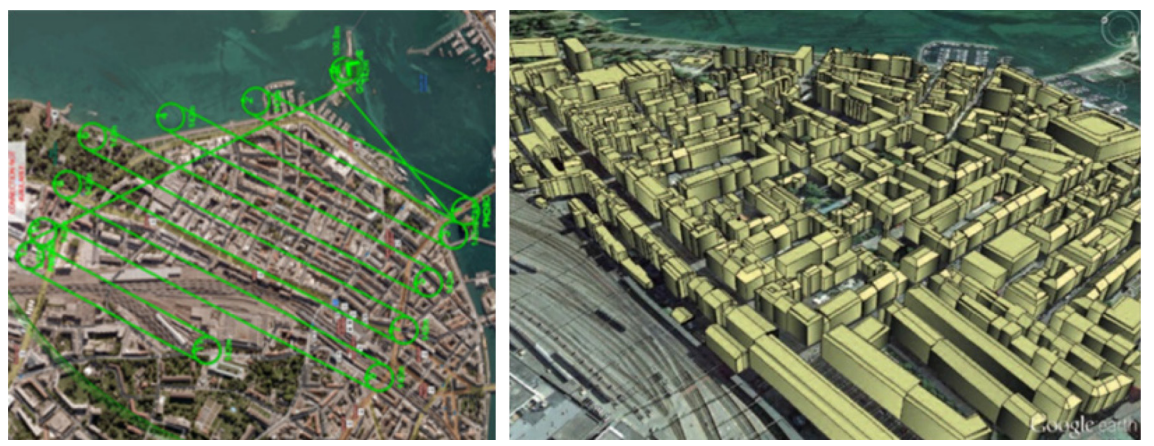

Figure 2: Flight planning of the UAV over the Pâquis neighborhood (left) and the raw 3D objects obtained (right), shown using the help of Google Earth.

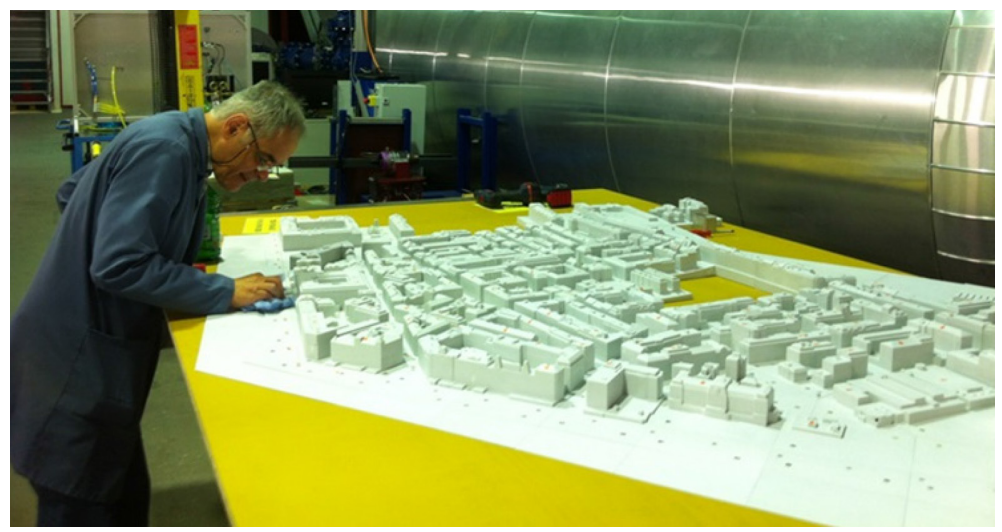

Figure 3: 3D model during assembly. 


\subsubsection{D CAD model for CFD studies}

At the present time, researchers are still working on the meshing of the model which has about 50 billion hexacore cells. In the mesh, a singular element has dimension of around 0.5 meter.

\subsection{UAV environmental measurements on town}

For the environmental measurements we used a UAV that allows stationary flights. This UAV is based on a hexacopter from the Fly-n-Sense company. The UAV can be equipped with PM10, O3 and NO2 sensors. The system records wind speed and different parameters such as temperature, pressure, position, altitude, etc. Thus we can obtain detailed maps of pollution concentration and phenomena related to particle movements. The pollutant diffusion can be outlined with a positioning tolerance smaller than one meter. For this project, the main objective of the UAV measurement campaign was to determine boundary conditions for CFD calculations at the borders of the Pâquis area. Figure 4 shows the UAV and a simulation of the air circulation around it which allows a better understanding of the measurement region.

Patrick Haas et al. presented the details of this work in the 32nd AIAA Applied Aerodynamics 2014 in Atlanta. The image on the right shows a simulation of the air movement around the UAV, which allows a better understanding of the measurement region.
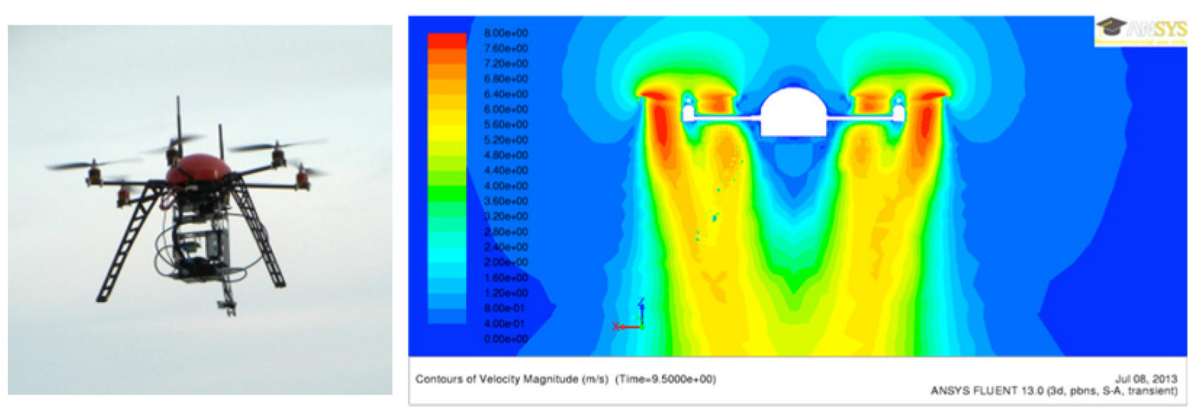

Figure 4: The UAV hexacopter carrying the NO2 sensor (left).

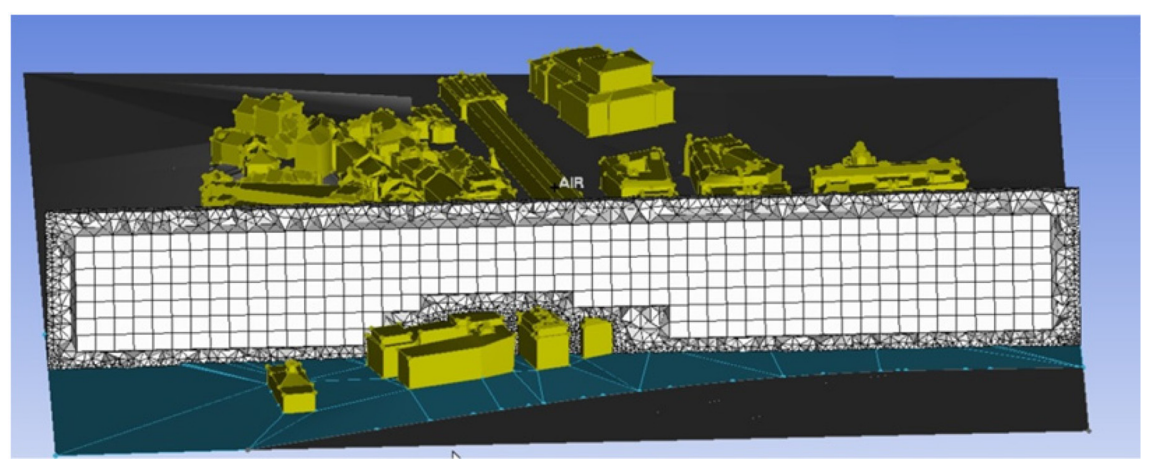

Figure 5: The 3D CAD Geneva Bank neighborhood. 


\subsection{Hardware and software choices}

At the beginning of this project, we decided to use open source CFD software called OpenFOAM [10]. Based on that choice, the team in charge of the computer hardware worked in two parallel methods. One is based on home hardware clusters and the second is based on local and commercial cloud solutions. In order to test the different computer infrastructures, we used an existing 3D CAD model of the Geneva Bank neighborhood, as shown in Fig. 5. This figure shows a cut plane of a first rough mesh (40 billion tetrahedral cells).

The study has shown that a solution is possible using a commercial cloud application: Amazon Elastic Compute Cloud (Amazon EC2) [14]. Based on Cloudflu, this is basically a series of Python scripts, which make the use of OpenFOAM with Amazon EC2 instances easier. We have a few scripts to [15]:

1. Upload the data

2. Automatically start and configure one or more EC2 instances which already have OpenFOAM installed (and link them together)

3. Decompose and distribute an OpenFOAM case

4. Run the solver and obtain the results (a typical simulation time takes about four hours for a price of about $12 \$$ ).

\subsection{Diffusion models in a first approach}

In order to develop a diffusion model and to determine the type of solver to be implemented in OpenFOAM, a simplified case, well documented in the literature, is used as a reference. We chose the well-documented study of dispersion around a single cube according to the work of RN Meroney \& T. Stathopoulos [16-19]. The results of these studies are derived from numerical simulations $[18,19]$ and others, and have the advantage of being the results of experiments conducted in wind tunnels $[16,17]$.

As a first step, we have verified on a hexahedral mesh of 0.5 billion cells, the convergence of the simulation OpenFOAM and compared the results with two commercial CFD software packages [11]: ANSYS Fluent and ANSYS CFX. To do that, we used the turbulence model $\mathrm{k}-\varepsilon$ RNG that is already implemented in commercial software. A simple diffusion model based on a scalar transport equation was implemented in OpenFOAM. The resulting code was called 'simpleTransportFoam'. The modified code simulates the turbulence and the scalar transport with an isotropic model. Despite this simplification, the results obtained with this routine are in good agreement with those obtained using commercial software.

Figure 6 shows the current streamlines and pollutant concentration around the cube obtained by simulation. Figure 7 shows the concentration of the pollutant on the cube and behind the cube (on left side of the figure) and in the wake (right side) versus the distance.
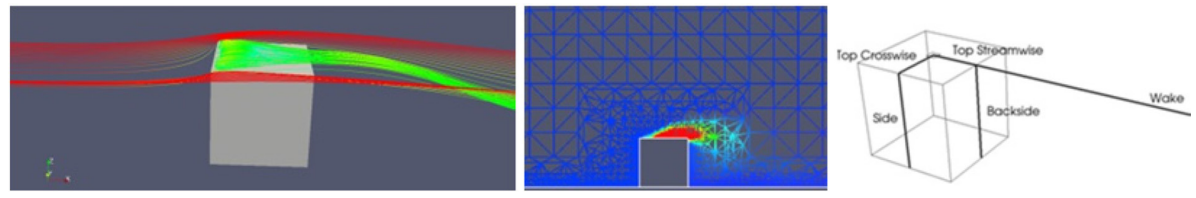

Figure 6: Streamlines around the cube (left) and the pollutant concentration (centre). 

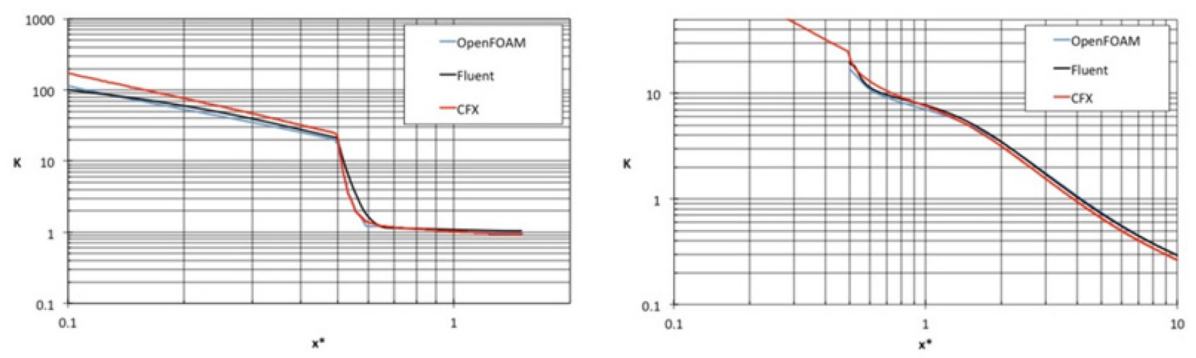

Figure 7: Pollutant concentration on the cube and behind the cube (left graph) and in the wake (right graph) versus the distance obtained with OpenFOAM, CFX, and Fluent.

These results are given without dimension, and they were obtained with different software: OpenFOAM, CFX and Fluent. As shown in Figs. 7 and 8, we obtain good agreement between the different solvers. More details concerning this work and also the influence of the meshing and the solver will be published shortly.

\subsection{Experimental measurements in wind tunnel}

\subsubsection{Experimental climatic conditions that were chosen}

To validate the fact that the CFD may help the town planner to estimate the pollution dispersions for their urban projects, we decided to use a real Geneva neighborhood that is strongly polluted even under the conditions of a strong east wind called 'bise'. The wind tunnel axis with respect to the 3D model was put in the same direction as the 'bise'. This is a well-defined experimental situation that can be compared to the simulation results. The authors would like to emphasize that the experimental situation does not have the objective of representing the real case of the Pâquis neighborhood but rather to establish a complex experimental case, which allows comparison with CFD investigations.

\section{SF6-Air mixture generation}

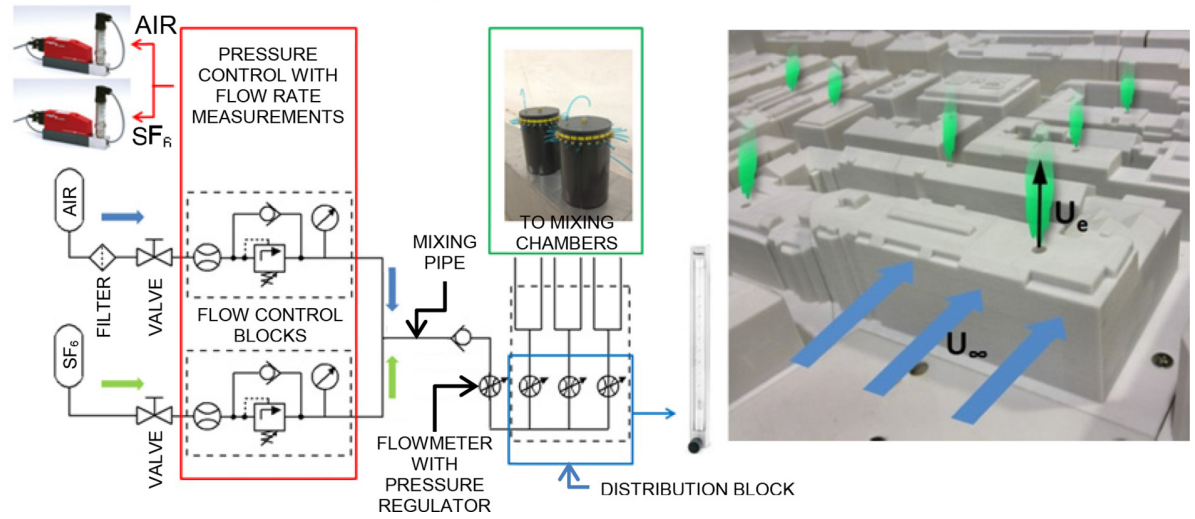

Figure 8: SF6 gas distribution system that allows each building to simulate the rejection of pollution. 


\subsubsection{The instrumented 3D model}

As shown in Fig. 8, the 3D model is equipped with an SF6 gas distribution system with three different tanks simulating three different pollutant mass flows rejected by the central heating systems. Depending on the type of furnace (oil or gas) and the building energy consumption, we classed the buildings in three categories. In the model, each of them was connected to an SF6 pressure bottle with identical plastic tubes - all the same length. This allows using the 3D model to simulate the rejection of pollution by the Pâquis neighborhood. In a next step, we will simulate car traffic pollution by using holes in the streets and injecting SF6.

To measure the SF6 in the 3D model, we used a Photoacoustic Gas Monitor INNOVA 1412i from LumaSense technologies. The gas inlet head is connected to a large automated three axes displacement system installed above the roof of the wind tunnel test section. The translator allows us to measure the SF6 concentration anywhere in the 3D model. Figure 9 shows the 3D model installed in the wind tunnel.

\section{EXPERIMENTAL VERSUS SIMULATIONS}

Since the end of 2014, we have the computer power (using the 'cloud') and an adequate meshing available to make the CFD simulations on the entire Pâquis neighborhood. Figure 10 shows the Pâquis meshing.

For these first comparisons between experimental measurements and simulation results, we used the rejection of pollution by the buildings in the model as shown in Fig. 9. The red dots in Fig. 11 show the geographical positions in the model where we measured the SF6
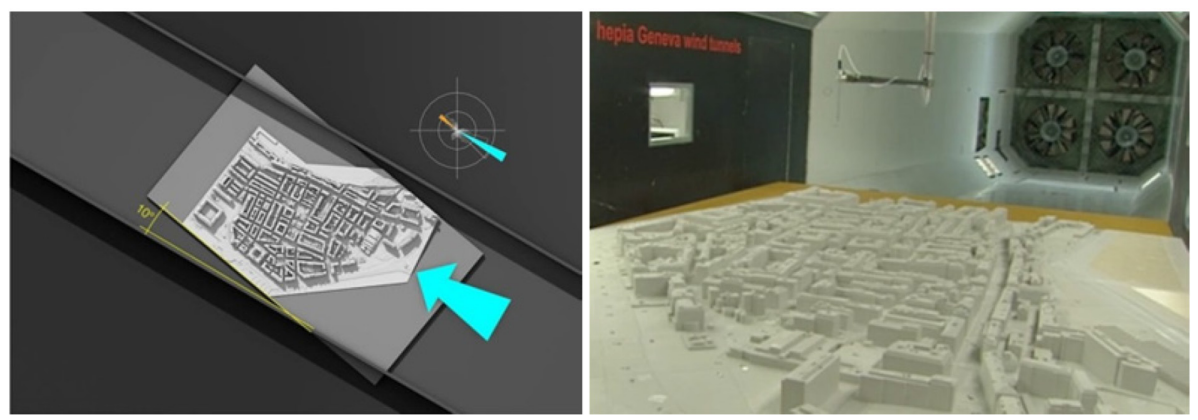

Figure 9: The 3D model in place inside the wind tunnel for SF6, wind speed fields, etc. measurements.
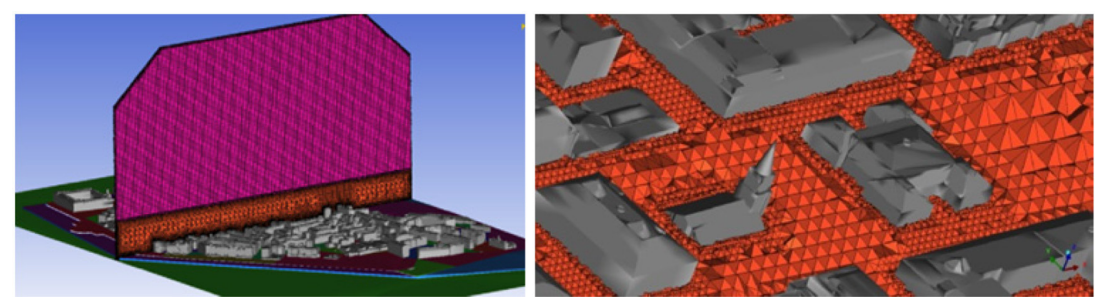

Figure 10: Pictures of the neighborhood meshing (57 Mio). 

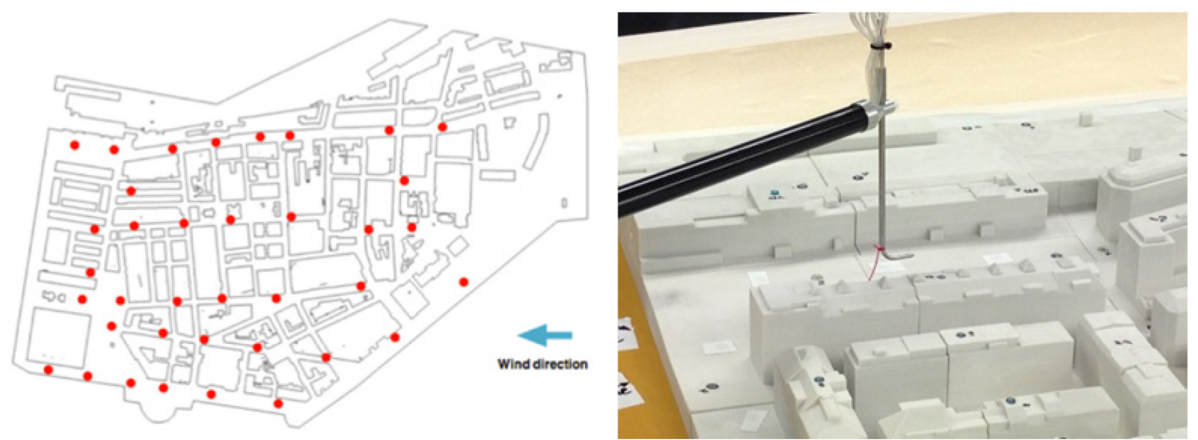

Figure 11: Left: geographical experimental measurement positions in the neighborhood model. Right: picture of the SF6 gas probe measurement system positioned on the Quai du Mont-Blanc.
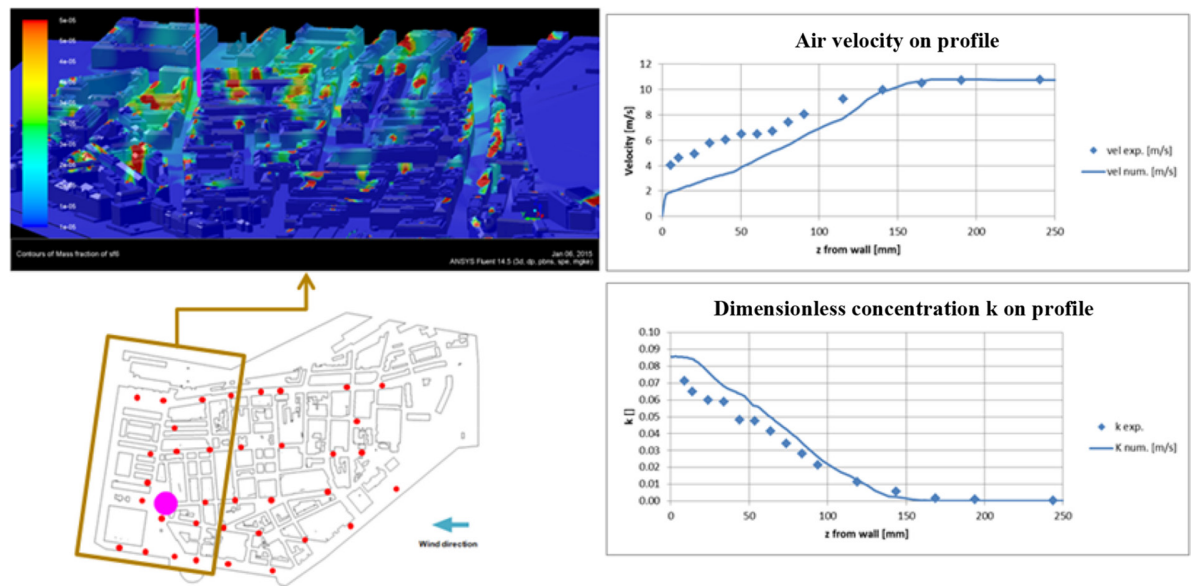

Figure 12: Left: the magenta point shows the geographic position, on Pâquis street (down) and dimensionless SF6 gas concentration on the buildings (up). Right: measurements of dimensionless gas concentration and wind speed as a function the height $\mathrm{z}$.

concentration, the wind speed fields and the pressure. The experimental measurements were carried out at $10 \mathrm{~m} / \mathrm{s}$, and the wind direction inside the wind tunnel is shown in Fig. 11.

Figure 12 shows the comparison between the experimental measurements (blue rhombi) and simulation results on a geographical point situated on Pâquis Street (blue lines). The agreement is very good, both for the wind fields and for the concentration of pollution (represented by the SF6 gas in the model). We would like to point out the excellent agreement of the results in the area far away from the right part of the model where the physical conditions are well defined. For each of the 37 points of comparisons, we obtained good agreement, which validates the use of the simulation as a tool to predict the urban climate.

Figure 13 shows the simulated wind speeds and directions (arrow vectors) and the concentration of pollution (SF6 gas concentration) represented by the color of the arrows. 


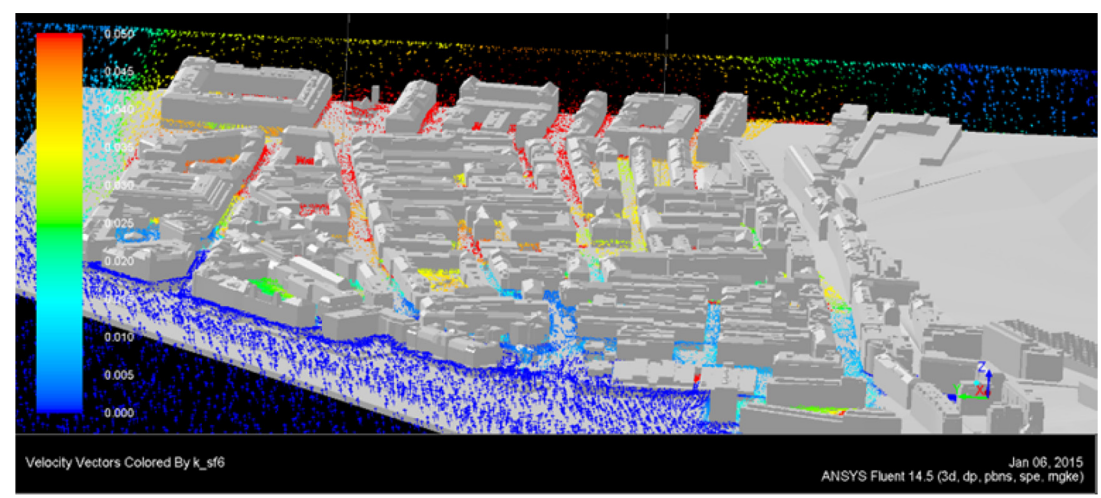

Figure 13: Wind speeds and directions (arrow vectors) and the concentration of pollution (SF6 gas concentration) represented by the color of the arrows.

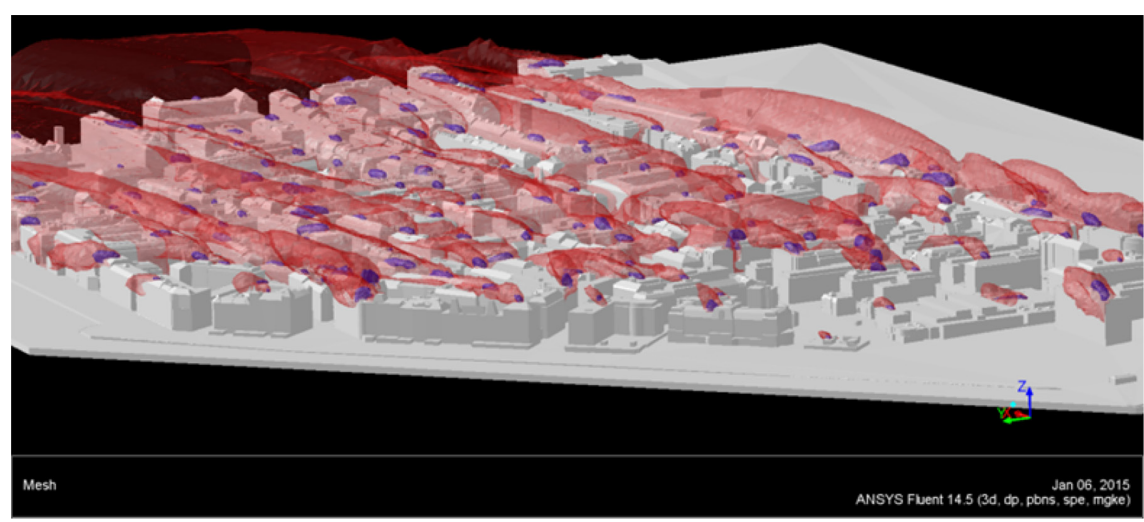

Figure 14: The image shows the simulated rejection of pollution by the buildings.

Figures 13 and 14 show the polluted gas dispersion emitted by the buildings in the Pâquis neighborhood model. The simulation shows the reduced wind and the accumulation of pollutants in the interior courtyards.

\section{PROGRESS OF THE PROJECT 'CLEAN CITY' / SIMULATIONS OF REPRESENTATIVE WEATHER SITUATIONS}

To make CFD simulations of representative weather conditions, we need to know the real physical conditions in the neighborhood, especially at the edges of the model. To do this, we first measured the pollution during 3 years in different Pâquis areas with eight fixed sensors at two meters above street level. In addition, we have developed an instrumented hexacopter UAV for measuring the needed physical parameters in situ. Measurements are underway.

\section{CONCLUSIONS AND CONTINUATION OF THE PROJECT}

Even if we have encountered and will encounter many difficulties, the 'Clean City' multidisciplinary project, started in 2011, produced its first results in the autumn 2015. We are 
confident that the proposed method will be a useful tool for urban planners and will be helpful. However, we understand that progress must be made to automate the CAD model file for the CFD simulation.

\section{ACKNOWLEDGMENTS}

This work is supported by the University of Applied Sciences Western Switzerland - HES-SO.

Thanks a lot to Karl Jauch for his help in the English redaction.

\section{REFERENCES}

[1] WHO Air quality guidelines for particulate matter, ozone, nitrogen dioxide and sulfur dioxide, Global update 2005, Summary of risk assessment, available at http://whqlibdoc.who.int/hq/2006/WHO_SDE_PHE_OEH_06.02_eng.pdf (accessed 12 April 2014).

[2] Etude d'impacts des équipements de climatisation sur la température de l'air dans l'agglomération parisienne, available at http://www.cnrm-game-meteo.fr/spip. php?article370 (accessed May 12, 2014).

[3] Adaptation au Changement CLIMatique de l'Aggloméeation Toulousaine, available at http://www.cnrm.meteo.fr/ville.climat/spip.php?rubrique46 (accessed May 12, 2014).

[4] Centre de Recherche en Climatologie, available at http://climatologie.u-bourgogne.fr/ (accessed May 12, 2014).

[5] Blocken, B., Tominaga, Y. \& Stathopoulos, T., CFD simulation of micro-scale pollutant dispersion in the built environment, available at: http://www.urbanphysics.net/2013 BAE_Virtual_Special_Issue__Preprint.pdf (accessed 9 Mai 2014).

[6] Huijbregts, Z., Blocken, B., Gousseau, P., Stathopoulos, T. \& van Heijst, G.J.F., CFD simulation of pollutant gas dispersion in downtown Montreal, Canada, available at http://sts.bwk.tue.nl/urbanphysics/Gas dispersion in downtown Montreal.htm (accessed May 12, 2014).

[7] International Association for Urban Climate, available at http://www.urban-climate.org/ (accessed May 12, 2014).

[8] Qualité de l'air 2011 - Service de protection de l'air, available at: http://ge.ch/air/media/air/files/fichiers/documents/rapport_ropag_2011.pdf (accessed May 12, 2014).

[9] SITG - Le territoire Genevois à la carte, available at http://ge.ch/sitg/ (accessed May 12, 2014).

[10] OpenFOAM is a free, open source CFD software package developed by OpenCFD Ltd at ESI Group and distributed by the OpenFOAM Foundation, available at http://www. openfoam.com/ (accessed May 12, 2014).

[11] ANSYS Fluent is commercial CFD simulation software used worldwide, available at http://www.ansys.com/ (accessed May 12, 2014).

[12] Gervaix, F. \& Ferreira, N., Rapid, Rich And Reliable Photogrammetry On Demand (R-Pod), World Engineers' Convention 2011, available at: http://www.r-pod.ch/wpcontent/uploads/2011/06/wec10Final00211.pdf (accessed 12 May 2014).

[13] Dellay, N. \& Triscone, G., R-Pod au service du "climat urbaain" avec Cean City. Geomatik Schweiz, pp. 454-459, 2013.

[14] Amazon Elastic Compute Cloud (Amazon EC2) is a web service that provides resizable compute capacity in the cloud. It is designed to make web-scale computing easier for developers, available at https://aws.amazon.com/ec2/ (accessed May 12, 2014).

[15] http://sourceforge.net/apps/mediawiki/cloudflu/index.php?title=Main_Page (accessed May 12, 2014). 
[16] Li, W.W. \& Meroney, R.N., Gas dispersion near a cubical model building. Part I Mean concentration measurements. Journal of Wind Engineering and Industrial Aerodynamics, 12, pp. 15-33, 1983.

[17] Li, W.W. \& Meroney, R.N., Gas dispersion near a cubical model building. Part II Concentration fluctuations measurements. Journal of Wind Engineering and Industrial Aerodynamics, 12, pp. 35-47, 1983.

[18] Tominaga, Y. \& Stathopoulos, T., Numerical simulation of dispersion around an isolated cubic building: model evaluation of RANS and LES. Building and Environment, 45, pp. 2231-2239, 2010.

[19] Baniotopoulos, C., Borri, C. \& Stathopoulos, T., Environmental wind engineering and design of wind energy structures. CISM International Centre for Mechanical Sciences, 531, ISBN 978-3-7091-0953-3, 2011. 